\title{
Daily functioning, verbal fluency and emotional functioning of patients with Parkinson's disease treated pharmacologically and with deep brain stimulation
}

\section{BACKGROUND}

The population aging phenomenon of western societies results in an increase in the number of neurodegenerative diagnoses. We aimed to examine the differences in daily emotional and cognitive functioning between patients with Parkinson disease treated with different methods and healthy adults of similar age.

PARTICIPANTS AND PROCEDURE

The participants $(N=52)$ were patients with Parkinson disease $(n=26)$ and healthy adults $(n=26)$ forming the control group. Daily, cognitive and emotional functioning were assessed with IADL, BDI II, COWAT and MMSE.

RESULTS

Significant differences $(t(50)=2.89, p=.006)$ in the daily functioning between clinical and control groups were found. The average scores evaluating the daily function of the patients treated pharmaceutically and surgically differed significantly $(t(49)=3.01, p=.004)$.

\section{CONCLUSIONS}

The study provides confirmation of the differences in the daily functioning of the patients, taking into account varied treatment. Undoubtedly, further research on this topic with a larger number of participants is required.

\section{KEY WORDS}

neurodegenerative disorders; depression; cognitive functioning; pharmacological treatment; activities of daily living 


\section{BACKGROUND}

Parkinson disease (PD) is a long-term neurodegenerative disorder of the central nervous system that mainly affects the motor system. The most distinguishable symptoms related to the motor system are slowed movement (bradykinesia), tremor and rigid muscles. Additionally, various symptoms not related to the motor system such as anxiety, depression, and various sleep and cognitive disorders are also frequently mentioned in the literature.

Furthermore, the population aging phenomenon of western societies results in a notable increase in the annual number of neurodegenerative diagnoses. Moreover, the average life expectancy of PD patients has significantly lengthened. According to the latest research, over $25 \%$ of $\mathrm{PD}$ patients live for more than 20 years (Hely, Reid, Adena, Halliday, \& Morris, 2008) after being diagnosed. The underlying factor enabling patients to live longer is pharmaceutical and medical technology development, mainly the fact that deep brain stimulation (DBS) has become much more accessible in the past 20 years. The DBS method has been approved by the US Food and Drug Administration (Gardner, 2013) as a standard procedure in Parkinson disease, tremor and dystonia treatment. DBS is a surgical procedure in which electrical leads are implanted into the deep brain structure to turn off or reduce activity of this structure. Then, programmable generators are usually placed underneath the skin of the chest (Asahi et al., 2014). Nevertheless, treatment can only alleviate the symptoms and increase the quality of patients' lives, as Parkinson disease is not treatable. The current research and clinical trials mainly focus on the analysis of the neurological aspects. Most of the studies of neuropsychological side effects after deep brain stimulation of the subthalamic nucleus (STN-DBS) report dysfunction in executive functions $(\mathrm{ExF})$, especially in verbal fluency (Boel et al., 2016; Fasano et al., 2010; Williams et al., 2011). Our study was designed to clarify the discrepancies in the research addressing the impact of DBS on the cognitive and emotional of PD patients, considering the fact that depression often co-occurs with Parkinson's disease.

\section{AIM OF THE STUDY}

We aimed to examine the differences in daily activities, emotional condition and cognitive abilities between patients diagnosed with Parkinson disease who had received various treatments (only pharmaceutical therapy [levodopa] or a DBS procedure as well) and healthy adults of similar age. Motor system disorders such as slowed movements, tremor or rigid muscles obviously affect activities of daily living among patients; therefore we aimed to examine the differences between groups in the extent to which patients are self-sufficient in daily activities (instrumental activities of daily living - IADL). As depression is the most frequently occurring disorder, we attempted to examine emotional functioning of patients, regarding different treatments that patients had received, as well as healthy participants. Also, various cognitive disorders such as attention deficiency, executive functions disorders and bradyphrenia are commonly present in Parkinson disease. Therefore, we also strived to establish the differences in the level of cognitive disposition between the clinical and control groups. Studies also provide evidence for impairments in the spontaneous production in speech in patients with PD, especially in action concepts (Humphries et al., 2019). Additionally, we investigated the differences in verbal fluency between the participants, as the decrease in the ability of the spontaneous enumeration of the words in a given category is one of the frequently mentioned side-effects of the deep brain stimulation procedure. The literature provides evidence that the decline of cognitive functioning in Parkinson disease also disrupts the daily functioning of the patients (Johnson, Lui, \& Yaffe, 2007; Mehta, Yaffe, \& Covinsky, 2002; Stuck et al., 1999). In addition, motor system disorders significantly diminish patients' abilities to independently fulfil more complex activities of daily living (Johnson et al., 2007). Therefore we aimed to establish whether there is a relationship between verbal fluency and the assessment of instrumental activities of daily living. The depression symptoms along with lower mood can also impair the ability to manage and complete numerous daily activities. The gradual loss of the ability to perform everyday activities triggers lower mood, and consequently it promotes the development of depression. Hence, we aimed to investing whether there would be a relationship between depression and the IADL and, if so, what the strength and the direction of this relationship would be.

\section{PARTICIPANTS AND PROCEDURE}

\section{PARTICIPANTS}

We recruited participants $(n=26)$ diagnosed with Parkinson disease among members of the non-profit organization for PD patients and their families in Poland. Our sample was represented by patients from Gdynia, Warsaw and Cracow. Inclusion criteria were: diagnosed idiopathic Parkinson disease, received only pharmaceutical therapy or DBS procedure as well, lack of co-occurs dementia, ready to provide consent to use data and participate in research. Individuals who failed to meet these requirements were not included in our study. In order to establish the control group, we invited to participate in our study adults of similar age and education level yet with- 
out any neurological disorders. We found no significant differences in terms of age of the participants $(t(50)=1.80, p=.077)$, number of gender representatives $\left(\chi^{2}(1)=.70, p=.402\right)$ or the educational level of the participants $\left(\chi^{2}(2)=4.06, p=.131\right)$.

\section{CLINICAL SAMPLE}

In our clinical sample $(n=26)$ the following groups were established according to the treatment methods patients had received. In the first group $(n=14)$ were patients who had only received pharmaceutics; the second group was represented by the patients whose pharmaceutical treatment had been supplemented with the deep brain stimulation procedure $(n=12)$. Once more, the sample was balanced in the number of gender representatives, there was an equal number of women $(n=13)$ and men $(n=13)$ and no significant differences in the education level were found, $\chi^{2}(1)=1.33, p=.249$. Approximately $54 \%$ of the participants in the clinical group held an academic degree, $35 \%$ of the patients had secondary education and $11 \%$ acquired professional education. The participants of our study were $M=63.42$ years old $(S D=8.09)$. The average duration of the Parkinson disease was $M=12.08$ years $(S D=6.14)$ and $M=5.50$ years $(S D=2.91)$ had passed since patients had undergone the DBS surgery. The vast majority of patients $(n=10)$ had undergone surgery to implant a stimulator into the subthalamic nucleus.

\section{CONTROL GROUP}

In the present study healthy adults $(n=26)$ were included in the control group. Even though it was quite unbalanced in terms of gender representatives, $62 \%$ of the control sample were females $(n=16)$ and $38 \%$ males $(n=10)$, yet the difference was not statistically significant $\left(\chi^{2}(1)=0.70, p=.402\right)$. The average age of the healthy participants was $M=67.78(S D=9.25)$. The education level details were as follows: $27 \%$ of the participants held an academic degree, 50\% had secondary education and the remaining $23 \%$ had professional education. The additional condition that was met before including anyone in the control group was a score on the MMSE scale equal to at least 23 points. It was necessary in order to eliminate possible dementia among the participants in the control group.

\section{MEASURES}

Instrumental Activities of Daily Living. To assess to what extent patients are self-sufficient in everyday living we used in our study the standardized scale Instrumental Activities of Daily Living (IADL; Rock- wood et al., 2005). The original scale presents excellent reliability, measured using Cronbach's $\alpha(\alpha=.99)$ and the test-retest method (.93) (Edwards, 1990; Ormel, Rijsdijk, Sullivan, van Sonderen, \& Kempen, 2002).

Beck Depression Inventory. Aiming to evaluate the emotional condition of the participants, we also applied the Beck Depression Inventory (BDI II), a method that is commonly used for the screening test, enabling one to evaluate the severity of the depression symptoms. The psychometric properties of the Polish adaptation conducted by Łojek and Stańczak (2019) revealed excellent reliability, Cronbach's $\alpha=.93$ in the clinical group and $\alpha=.91$ in the control group. What is more, a satisfactory test-retest result was achieved (.86).

Controlled Oral Word Association Test. In order to assess the cognitive functioning of the participants, we used the Controlled Oral Word Association Test (COWAT). The procedure of the COWAT requires patients to enumerate as many words as they can starting with a given letter (to evaluate the phonemic verbal fluency) or belonging to a particular category (which allows semantic verbal fluency to be assessed). The score of the COWAT is calculated as the total number of words from both trials and defined as word production (WP) (Jodzio, 2006).

Mini-Mental State Examination. For the global assessment of the cognitive abilities we used the MiniMental State Examination (MMSE). The MMSE scale consists of 30 questions. The examination procedure lasts about 5 minutes and allows one to appraise several cognitive abilities such as orientation in time and space, attention and concentration, calculation, shortterm memory, constructional praxis and language abilities (naming, reading, writing) (Stańczak, 2010). The maximum score one can achieve is 30 points. According to the research findings, a number of points less than 24 may indicate dementia (Treder \& Jodzio, 2013).

In addition, to ascertain some basic demographic information an authorial questionnaire was constructed, including questions about gender, age, educational level, marital status and the place of residence. Additionally, the version dedicated for the clinical group contained questions about whether one is taking medicaments containing levodopa (L-DOPA) on a regular basis, the number of years the disease had lasted and when the DBS took place (if applicable).

\section{PROCEDURE}

In the present study, the same procedure was applied to each participant. At the start, each participant was invited to the same laboratory office ensuring the deletion of possible distractors and ensuring comfortable conditions throughout the study procedure. No benefits were offered. At first, the researcher had
Daily living of patients with Parkinson's disease treated with different methods 
Carla Wąs,

Aleksandra Obuchowska provided each participant with the basic information about the aim and specific details of the study. Secondly, the researcher emphasized the confidentiality of the collected data and the possibility to end participation in the study at any time. Next, each participant was asked to sign the written consent form for participation in the study. The form included the information that the obtained results will only be used for scientific purposes, and that receiving feedback about the results of the whole study is possible upon request. Next, participants assigned to the control group $(n=26)$ and those from the clinical group who had received only pharmaceutics $(n=14)$ were asked to complete the MMSE scale. Taking into consideration that patients classified for surgical treatment are routinely diagnosed for dementia (due to its frequent co-occurrence with Parkinson disease) we did not ask subjects who underwent the DBS procedure to complete the MMSE. Then, all of the participants completed the Instrumental Activities of Daily Living, and after that the Controlled Oral Word Association Test. Finally, participants were asked to complete BDI II. At the end, the researcher asked each participant to fill in the authorial questionnaire including questions about basic sociodemographic data.

\section{RESULTS}

Firstly, using R language and environment for statistical computing (R Core Team, 2019) data were tested against normality. A logarithmic transformation of a variable reflecting IADL results was necessary. A new, transformed variable was used in all further analysis. All the necessary descriptive statistics are provided in Table 1. To address the research question, whether there is a relationship between depression and the IADL and if there is an association between verbal fluency and the assessment of instrumental activities of daily living, a correlation analysis was performed. The analysis indicates a moderate, positive relationship between verbal fluency measures, $r_{\mathrm{s}}=.52$,
95\% CI $[.17, .76], p=.009$ as both tests measure similar aspects of the executive functions. What is more, the analysis revealed a moderate negative correlation, $r_{\mathrm{s}}=-.46,95 \% \mathrm{CI}[-.72,-.08], p=.052$, between IADL and BDI II. Presumably, depression symptoms such as lack of motivation and insomnia are conducive to the patients being less independent and self-sufficient in daily activities. The remaining correlation coefficients were not statistically significant in either the clinical sample or in the control group. The values of correlation coefficients suggest a rather weak relationships between variables (see Appendix 1 and 2).

In order to establish the differences between the two groups in the extent to which patients are selfsufficient in daily activities and what the differences in patients' emotional functioning are, independent means tests were applied. Also, Student's $t$-test was applied to investigate differences in verbal fluency between the participants in the two groups. The IADL scores were significantly lower among PD patients, $t(50)=2.89, p=.006$. In the present study, results of the Beck Depression Inventory were not significantly different between the two groups, $t(50)=1.32, p=.195$. What is more, there were no significant differences in the COWAT test, regardless of the phonemic $(t(50)=0.03, p=.974)$ or semantic fluency $(t(50)=1.41, p=.165)$ between the clinical and control group. In the next step we decided to perform a one-way independent analysis of variance. Taking into account the rather small sample size, use of a parametric method might seem disputable. Yet, considering the results of the normality tests performed on our data, and the fact that ANOVA is a generally robust method, our choice appeared to be justified. The three groups were established according to the treatment methods patients had received, pharmaceutics only $(n=14)$ or medicaments enhanced with the DBS surgery $(n=12)$ compared to the control group $(n=26)$. Prior to testing the ANOVA model, in order to answer the research question, we tested age differences between three groups, $F(2,49)=3.85$, $p=.028$. The Tukey HSD test indicates a significant

Table 1

Means and standard deviations in analysed sample $(N=52)$

\begin{tabular}{|c|c|c|c|c|c|c|c|c|}
\hline & \multicolumn{4}{|c|}{$\begin{array}{c}\text { Clinical sample } \\
\qquad n=26\end{array}$} & \multicolumn{4}{|c|}{$\begin{array}{c}\text { Control group } \\
\quad n=26 \\
\end{array}$} \\
\hline & Min & Max & $M$ & $S D$ & Min & Max & $M$ & $S D$ \\
\hline IADL & 16 & 27 & 24.65 & 2.99 & 23 & 27 & 26.50 & 0.95 \\
\hline COWAT (phonemic verbal fluency) & 5 & 21 & 13.69 & 4.17 & 5 & 20 & 13.65 & 4.36 \\
\hline COWAT ${ }_{\text {(semantic verbal fluency) }}$ & 6 & 26 & 15.96 & 5.90 & 3 & 33 & 18.46 & 6.86 \\
\hline BDI II & 1 & 26 & 11.35 & 6.84 & 9 & 24 & 8.81 & 7.09 \\
\hline
\end{tabular}

Note. IADL - Instrumental Activities of Daily Living, BDI II - Beck Depression Inventory, COWAT - Controlled Oral Word Association Test. 
difference $(p=.023)$ between patients receiving only pharmaceutics $(M=67.77)$ and patients who underwent surgery $(M=59.75)$. The means of IADL were as follows: $M=25.07, S D=3.20$ among patients receiving only pharmaceutics, and $M=24.17, S D=2.79$ among patients who underwent DBS, whereas the average score in the control group was $M=25.50, S D=0.95$. The means differed significantly, $F(2,49)=4.55$, $p=.015$. The planned comparisons of the means revealed that the means of IADL of patients treated pharmaceutically and surgically differed significantly $(t(49)=3.01, p=.004)$. The average scores of the Beck Depression Inventory were not significantly different $F(2,49)=1.31, p=.278$. Neither the phonemic verbal fluency $(F(2,49)=0.25, p=.780)$ nor semantic verbal fluency $(F(2,49)=0.99, p=.381)$ significantly differed among patients receiving varied treatments.

\section{DISCUSSION}

The present study was designed and conducted to deepen the characteristics of daily functioning, emotional state and cognitive abilities of patients diagnosed with Parkinson disease. What is more, we aimed to investigate the differences in the abovementioned areas between individuals receiving various treatment methods and healthy adults. Such studies play a vital role in differential diagnosis development, enabling one to identify possible differences between patients with the same diagnosis. Similar significant differences in the daily functioning of the PD patients have been reported by Lorencowicz (2012), suggesting that Parkinson disease remarkably hinders the ability to independently fulfil daily tasks. In the mentioned study, it was suggested that elderly people of the same age, yet not suffering from Parkinson disease, are far more self-sufficient in housekeeping, cooking or doing the grocery shopping. However, there were no significant differences in the daily living activities between PD patients treated pharmacologically and with DBS. Possibly, the self-assessment procedure of IADL might not provide a complete and objective evaluation (Shulman et al., 2006). Surprisingly, in our study, there were no significant differences between control and clinical groups in terms of depression symptoms severity. Furthermore, there were no significant differences in the emotional state between PD patients who had received various treatments. Possibly, the participants in our clinical sample were not suffering from depression. The average score on BDI II in the analysed clinical sample was $M=11.35, S D=6.84$. Yet, it is worth considering the following interpretation of the average scores of BDI II based on the meta-analysis: 0-13 minimal or no depression, 14-19 mild depression, 20-28 moderated depression, 29-63 severe depression. What is more, a systematic review of the inventory suggests that the general cut-off point for a minimal depression is 14.06 (von Glischinski, von Brachel, \& Hirschfeld, 2018). However, the meta-analysis can only be considered as a general guideline, as it was performed on data regarding patients diagnosed for depression without co-occurring neurodegenerative disorders compared to our study. In the present study we analysed the BDI II scores according to the following guidelines, 0-11 minimal depression, 12-19 mild depression, 20-25 moderate depression, 26-63 severe depression, provided by the authors of the Polish adaptation of BDI II (Łojek \& Stańczak, 2019). According to a metanalysis (Slaughter, Slaughter, Nichols, Holmes, \& Martens, 2001) in approximately $42 \%$ of cases, depression co-occurs with Parkinson disease. What should also be mentioned is the selection method used in our study. Most of the participators were members of the non-profit organizations for sufferers and providing them with support. Particularly, social support is a crucial factor preventing depression development (Michalska-Leśniewicz \& Gruszczyński, 2010). Possibly, other psychological factors also influenced the results of the study. In the study of Mohseni, Iranpour, Naghibzadeh-Tahami, Kazazi, and Borhaninejad (2019) the authors consider the meaning in life and its significant relationship with resilience, which are associated with better psychological adaptation and a lower level of depression in the elderly.

A vast amount of research proves the decrease of verbal fluency resulting from deep brain stimulation surgery. Unexpectedly, the present results indicate insignificant differences in the verbal fluency between PD patients treated with different methods, as well as between the control and clinical group. Apparently, the procedure of the COWAT test engages numerous cognitive capacities, especially executive functions and working memory capabilities. Therefore, it is likely that in general, cognitive abilities of the individuals participating in our study were quite high. Importantly, numerous non-profit organizations for the PD patients provide various training, enabling maintenance of cognitive abilities. It is crucial to conduct a replication of the study, recruiting a larger number of participants, and controlling the possible confounding variables such as participation in the cognitive abilities' training. Additionally, the study conducted by Herrera, Cuetos, and Ribacoba (2012) reported differences in the phonemic fluency between PD patients on and off medication. When patients were off, they generated fewer words, compared to when they were on dopamine medication. The insignificant differences between the clinical and the control group in our study may also be a consequence of the insufficient statistical power and the significant differences in terms of age of the participants. However, the results reflect the clinical reality and the fact that younger patients are classified for deep brain stimulation surgery more often. What
Daily living of patients with Parkinson's disease treated with different methods 
Carla Wąs, Aleksandra Obuchowska should be emphasized is that patients declared for DBS surgery are routinely diagnosed for dementia, as its co-occurrence with Parkinson disease disqualifies patients from the surgery. Therefore, we did not ask participants who had undergone the surgery to complete the MMSE. However, dementia could have developed during the treatment process. Eliminating dementia among patients in the course of DBS treatment is troublesome in practice, as it may require repeated usage of the same or very similar diagnostic methods. The reiterated usage of the comparable tests is likely to blur the diagnosis or result in appearance of the practice or boredom effects. Our study has the advantage of careful selection of the participants, scrutinized methodological choices and the high applicability of the results, for practitioners as well as researchers. Attention should be drawn to the fact that the participants we had recruited to the control group were similar in age and educational level and the sample was balanced in terms of gender, to ensure elimination of possible interference in verbal fluency test results (Szepietowska \& Gawda, 2011). We would also like to highlight the fact that the procedure was standardized for all of the participants. What is more, the methodology was designed in a way that minimizes boredom or fatigue. In conclusion, the present study revealed significant differences in the daily functioning between participants in the clinical and control group. The participants in both groups were in a good emotional state. Statistical analysis suggests no significant differences in the level of verbal fluency between the individuals in the two groups. No relationship was discovered between the daily activities and verbal fluency. What is more, in the present study no significant differences in the cognitive abilities, emotional state or daily living activities between PD patients receiving only medicaments and those who had undergone the DBS surgery were found. The average sample size, and the lack of replications should be mentioned as the crucial limitations of the study. It would be reasonable to conduct a replication including a larger number of participants. Moreover, adding a controlling variable (on/off medication) among the patients may considerably improve the findings, providing us with an important insight. Finally, in the forthcoming research, emphasis should be put on the control of possible confounding variables such as participation in cognitive abilities' training.

\section{REFERENCES}

Asahi, T., Nakamichi, N., Takaiwa, A., Kashiwazaki, D., Koh, M., Dougu, N., Takashima, S., Tanaka, K., \& Kuroda, S. (2014). Impact of bilateral subthalamic stimulation on motor/cognitive functions in Parkinson's disease. Neurologia Medico-chirurgica, 54, 529-536. https://doi.org/10.2176/nmc.oa.2013-0364
Boel, J., Odekerken, V., Geurtsen, G., Schmand, B., Cath, D. C., Figee, M., van den Munckhof, P., de Haan, R. J., Schuurman, P. R., de Bie, R. M., \& NSTAPS study group (2016). Psychiatric and social outcome after deep brain stimulation for advanced Parkinson's disease. Movement Disorders, 31, 409-413. https://doi.org/10.1002/mds.26468

Cumming, G. (2014). The new statistics: Why and how. Psychological Science, 25, 7-29. https://doi. org/10.1177/0956797613504966

Edwards, M. M. (1990). The reliability and validity of self-report activities of daily living scales. Canadian Journal of Occupational Therapy, 57, 273-278. https://doi.org/10.1177/000841749005700507

Fasano, A., Romito, L., Daniele, A., Piano, C., Zinno, M., Bentivoglio, A. R., \& Albanese, A. (2010). Motor and cognitive outcome in patients with Parkinson's disease 8 years after subthalamic implants. Brain, 133, 2664-2676. https://doi.org/10.1093/brain/awq221

Gardner, J. (2013). A history of deep brain stimulation. Technological innovation and the role of clinical assessment tools. Social Studies of Science, 43, 707728. https://doi.org/10.1177/0306312713483678

Hely, M. A., Reid, W. G., Adena, M. A., Halliday, G. M., \& Morris, J. G. (2008). The Sydney multicenter study of Parkinson's disease: The inevitability of dementia at 20 years. Movement Disorders, 23, 837844. https://doi.org/10.1002/mds.21956

Herrera, E., Cuetos, F., \& Ribacoba, R. (2012). Verbal fluency in Parkinson's disease patients on/ off dopamine medication. Neuropsychologia, 50, 3636-3640. https://doi.org/10.1016/j.neuropsychologia.2012.09.016

Humphries, S., Klooster, N., Cardillo, E., Weintraub, D., Rick, J., \& Chatterjee, A. (2019). From action to abstraction: The sensorimotor grounding of metaphor in Parkinson's disease. Cortex, 121, 362-384. https://doi.org/10.1016/j.cortex.2019.09.005

Jodzio, K. (2006). Neuropoznawcze korelaty spadku fluencji słownej po udarze prawej półkuli mózgu [Neurocognitive correlates of reduction of verbal fluency following right-hemisphere stroke]. Studia Psychologiczne, 44, 5-18.

Johnson, J. K., Lui, L. Y., \& Yaffe, K. (2007). Executive function, more than global cognition, predicts functional decline and mortality in elderly women. The Journals of Gerontology Series A: Biological Sciences and Medical Sciences, 62, 1134-1141. https:// doi.org/10.1093/gerona/62.10.1134

Lorencowicz, R. (2012). Wybrane uwarunkowania jakości życia w chorobie Parkinsona [Selected determinants of quality of life in Parkinson's disease]. Pielęgniarstwo Neurologiczne i Neurochirurgiczne, 1, 48-57.

Łojek, E., \& Stańczak, J. (2019). Inwentarz Depresji Becka - drugie wydanie [Beck Depression Inventory - second edition; BDI-II]. Warszawa: Pracownia Testów Psychologicznych. 
Mehta, K. M., Yaffe, K., \& Covinsky, K. E. (2020). Cognitive impairment, depressive symptoms, and functional decline in older people. Journal of the American Geriatrics Society, 50, 1045-1050. https:// doi.org/10.1046/j.1532-5415.2002.50259.x

Michalska-Leśniewicz, M., \& Gruszczyński, W. (2010). Czynniki psychologiczne w depresji [Psychological factors in depression]. Psychiatria, 7, 95-103.

Mohseni, M., Iranpour, A., Naghibzadeh-Tahami, A., Kazazi, L., \& Borhaninejad, V. (2019). The relationship between meaning in life and resilience in older adults: a cross-sectional study. Health Psychology Report, 7, 133-138. https://doi.org/10.5114/ hpr.2019.85659

Ormel, J., Rijsdijk, F. V., Sullivan, M., van Sonderen, E., \& Kempen, G. I. (2002). Temporal and reciprocal relationship between IADL/ADL disability and depressive symptoms in late life. The Journals of Gerontology Series B: Psychological Sciences and Social Sciences, 57, 338-347. https://doi.org/10.1093/ geronb/57.4.P338

R Core Team (2019). R: A language and environment for statistical computing. Vienna, Austria: R Foundation for Statistical Computing. Retrieved from https://www.Rproject.org/.

Rockwood, K., Song, X., MacKnight, C., Bergman, H., Hogan, D. B., McDowell, I., \& Mitnitski, A. (2005). A global clinical measure of fitness and frailty in elderly people. Canadian Medical Association Journal, 173, 489-495. https://doi.org/10.1503/cmaj.050051

Shulman, L. M., Pretzer-Aboff, I., Anderson, K. E., Stevenson, R., Vaughan, C. G., Gruber-Baldini, A. L., Reich, S. G., \& Weiner, W. J. (2006). Subjective report versus objective measurement of activities of daily living in Parkinson's disease. Movement Disorders, 21, 794-799. https://doi.org/10.1002/mds. 20803

Slaughter, J. R., Slaughter, K. A., Nichols, D., Holmes, S. E., \& Martens, M. P. (2001). Prevalence, clinical manifestations, etiology, and treatment of depression in Parkinson's disease. The Journal of Neuropsychiatry and Clinical Neurosciences, 13, 187-196. https://doi.org/10.1176/jnp.13.2.187

Stańczak, J. (2010). MINIMENTAL - Krótka Skala Oceny Stanu Umystowego. Polska normalizacja [MiniMental State Examination. Polish standardization]. Warszawa: Pracownia Testów Psychologicznych PTP.

Stuck, A. E., Walthert, J. M., Nikolaus, T., Bula, C. J., Hohmann, C., \& Beck, J. C. (1999). Risk factors for functional status decline in community-living elderly people: a systematic literature review. Social Science \& Medicine, 48, 445-469. https://doi. org/10.1016/S0277-9536(98)00370-0

Szepietowska, E. M., \& Gawda, B. (2011). Ścieżkami fluencji werbalnej [In the paths of verbal fluency]. Lublin: Wydawnictwo Uniwersytetu Marii CurieSkłodowskiej.
Treder, N., \& Jodzio, K. (2013). Heterogeniczność funkcjonowania poznawczego i jego zaburzeń u osób starszych [The heterogeneity of cognitive functioning and its disorders in elderly people]. Psychiatria i Psychoterapia, 9, 3-13.

von Glischinski, M., von Brachel, R., \& Hirschfeld, G. (2018). How depressed is "depressed"? A systematic review and diagnostic meta-analysis of optimal cut points for the Beck Depression Inventory revised (BDI-II). Quality of Life Research, 28, 11111118. https://doi.org/10.1007/s11136-018-2050-x

Williams, A., Arzola, G., Strutt, A., Simpson, R., Jankovic, J., \& York, M. K. (2011). Cognitive outcome and reliable change indices two years following bilateral subthalamic nucleus deep brain stimulation. Parkinsonism \& Related Disorders, 17, 321-327. https:// doi.org/10.1016/j.parkreldis.2011.01.011
Daily living of patients with Parkinson's disease treated with different methods 


\section{APPENDIX 1}

Means, standard deviations, and correlations with confidence intervals in clinical sample $(n=26)$

\begin{tabular}{|c|c|c|c|c|c|}
\hline Variable & $M$ & $S D$ & 1 & 2 & 3 \\
\hline 1. COWAT (phonemic verbal fluency) & 13.65 & 4.36 & & & \\
\hline 2. COWAT (semantic verbal fluency) & 18.46 & 6.86 & $\begin{array}{c}.52^{* *} \\
{[.17, .76]}\end{array}$ & & \\
\hline 3. BDI II & 8.81 & 7.09 & $\begin{array}{c}.26 \\
{[-.15, .58]}\end{array}$ & $\begin{array}{c}-.06 \\
{[-.44, .34]}\end{array}$ & \\
\hline 4. IADL & 1.42 & 0.02 & $\begin{array}{c}-.06 \\
{[-.44, .34]}\end{array}$ & $\begin{array}{c}-.01 \\
{[-.40, .37]}\end{array}$ & $\begin{array}{c}-.46^{*} \\
{[-.72,-.08]}\end{array}$ \\
\hline
\end{tabular}

Note. Values in square brackets indicate the $95 \%$ confidence interval for each correlation. The confidence interval is a plausible range of population correlations that could have caused the sample correlation (Cumming, 2014). ${ }^{*} p<.05,{ }^{* *} p<.01$.

APPENDIX 2

Means, standard deviations, and correlations with confidence intervals in control group $(n=26)$

\begin{tabular}{|c|c|c|c|c|c|}
\hline Variable & $M$ & $S D$ & 1 & 2 & 3 \\
\hline 1. COWAT (phonemic verbal fluency) & 13.69 & 4.17 & & & \\
\hline 2. COWAT (semantic verbal fluency) & 15.96 & 5.90 & $\begin{array}{c}.39 \\
{[-.00, .67]}\end{array}$ & & \\
\hline 3. BDI II & 11.35 & 6.83 & $\begin{array}{c}.08 \\
{[-.32, .45]}\end{array}$ & $\begin{array}{c}-.05 \\
{[-.43, .34]}\end{array}$ & \\
\hline 4. IADL & 1.39 & 0.06 & $\begin{array}{c}.35 \\
{[-.05, .65]}\end{array}$ & $\begin{array}{c}.38 \\
{[-.00, .67]}\end{array}$ & $\begin{array}{c}-.31 \\
{[-.63, .08]}\end{array}$ \\
\hline
\end{tabular}

Note. Values in square brackets indicate the $95 \%$ confidence interval for each correlation. The confidence interval is a plausible range of population correlations that could have caused the sample correlation (Cumming, 2014 ). ${ }^{*} p<.05,{ }^{* *} p<.01$. 